\title{
Casualty departments
}

\author{
F. C. Durbin \\ F.R.C.S. \\ Senior Orthopaedic Surgeon, \\ Royal Devon and Exeter Hospital, and Princess Elizabeth \\ Orthopaedic Hospital, Exeter
}

ACCIDENT services at the present time are in the front line of criticism. In the press, both lay and medical, articles appear and documentaries about them are shown on television. This is because of deficiencies which have recently become very much aggravated by staffing problems but there is no doubt that too little attention has been paid to the accident services and that they have been insufficiently financed; it is no exaggeration to describe them as the Cinderellas of the National Health Service.

Casualty departments began as reception and first-aid rooms in hospitals where casual attenders came to receive urgent attention. These rooms were staffed by dedicated members of the nursing staff who often remained in office for many years and acquired much wisdom and experience. These worthy ladies acted as sorters, diagnosing serious from trivial cases, sewed up wounds, administered nitrous oxide anaesthesia and were capable of carrying out a number of procedures now permitted to be carried out only by doctors. In the departments of the teaching hospitals they played a very important part in the training of many casualty dressers and casualty officers who passed through their departments. Medical supervision of the departments was very haphazard and in many hospitals was shared amongst the resident house surgeons and house physicians who were expected to do a stint in casualty as part of their programme of work, a practice which still prevails in some hospitals at the present time.

Orthopaedic surgeons have played their part in developing accident services ever since Sir Robert Jones organized the first one during the building of the Manchester Ship Canal in the late nineteenth century. His work and also his military service during the First World War were really the start of an organization of planned continuous care of the seriously injured patient from emergency pri nary treatment through reconstructive surgery to rehabilitation, by a single clinical team. After the war, Sir Robert Jones devoted his energies to setting up a national network of orthopaedic hospitals and clinics. Before 1948, when the National Health Service was formed, progress was very slow in developing the accident services although a memorandum on them had been prepared by the British Orthopaedic Association in 1943. The accident services, however, were being strained by the start of an epidemic of civilian injuries caused by large numbers of motor vehicles and the increasing mechanization of industry. The effect of the National Health Service and its bonus of free medical advice and treatment for everybody led to the departments being besieged by large numbers of patients with the demand for simple first-aid, instant medical attention or advice for every minor injury, illness or complaint. The ancient casualty rooms became outdated and overwhelmed in a very short time and the services which they provided have been quite unable to cope with the ever increasing influx. Fortunately at this time it was possible to staff the departments with doctors from overseas who came to England for higher degrees, particularly the FRCS, and worked in the departments while they were taking their examinations. They filled the casualty officer grades and registrar grades throughout England for many years and some occupants of the posts remained in them for longer than it was desirable for them to do so. An alteration in the regulations for the FRCS and a restriction on emigration by Pakistan and India reduced the numbers of overseas doctors who were available to fill these posts. In consequence a crisis arose and this is still continuing and is responsible for the present anxiety.

Following another memorandum on the accident services from the British Orthopaedic Association in 1959 the Platt report on the accident and emergency services in 1962 went into all the problems of the accident services in great detail and put forward many recommendations which are really as sound today as they were in 1962 . However, in 1969 because so little had been done to implement these recommendations, some members of the British Orthopaedic Association felt that action was urgently needed and an accident services subcommittee was formed by the executive, mainly to act as a ginger group. Staffing appeared to be the major problem, particularly in casualty departments, and it was felt that if this was put right, then general improvements would 
follow. No large scale detailed knowledge of the staffing of casualty departments was available and it was felt that this information might be valuable and so a pro forma was drawn up and sent out to every hospital with an accident department, or accident service, and with this you are familiar. All I can do in the limited time available is just to tell you what information we have obtained.

The information has been put into a computer at Exeter by Dr Dilwyn Morgan of the Institute of Biometry and Community Medicine. My colleague Mr Scott, however, analysed 125 pro formas without assistance and he drew up a preliminary report for which I am most grateful. I must thank all those who have done their best to fill up the pro formas. It is not easy to compile one which is easily understood and I think you did very well.

An analysis has been made of 228 out of 321 departments, nearly $70 \%$ (two departments have no accident and emergency departments) and the full report will be published later. The departments came from all the major population areas in England and Wales including teaching and non-teaching hospitals and comprised very large and very small departments. It has been the most comprehensive survey so far reported. The returns of the regions are as shown, Table 1 . It is interesting that although $85 \%$ of these departments were in clinical charge of a consultant orthopaedic surgeon, 200 departments had no paid sessions for their work. Moreover, $50 \%$ of the accident centres were below the establishment for orthopaedic surgeons recommended by the Platt report nearly 10 years ago.

TABLE 1. Analysis of 125 departments $-85 \%$ in clinical charge of orthopaedic surgeons; $31,480,000$ population served

\begin{tabular}{cc}
\hline New attendances & $1969(10 \%$ of resident population $)$ \\
\hline Percentage & New attendances per annum \\
\hline 60 & $<25,000$ \\
27 & $25-39,000$ \\
13 & $<40,000$ \\
\hline
\end{tabular}

\section{Workload}

The departments served a resident population of $52,722,243$ people. In 1969 new attendances in these departments represented $10 \%$ of the resident population.

Sixty-three percent of 228 departments had less than 25,000 new attendances per year, $25 \%$ had 25 39,000 attendances and $12 \%$ over 40,000 . Admissions from these departments excluding medical and surgical emergencies previously seen and referred by general practitioners averaged $8 \%$ new cases. An average of $32.4 \%$ new attendances received only simple advice or first-aid without the use of X-ray, plaster, anaesthetic or operating facilities. The remaining $60 \%$ may therefore be assumed to have required the use of some of the specific hospital out-patient facilities, mainly X-rays. Previous studies have shown that the proportion of new patients referred for further care to trauma clinics constituted between 5 and $20 \%$.

\section{Staffing}

Staffing establishments of 125 departments totalled 482 full-time equivalents of which $63 \%$ were senior house officers. Ninety-eight of these senior house officer posts, comprising one-seventh of the total establishment, had been vacant for a month or more during the previous year. Five departments were closed at night for lack of staff, 214 departments were always open and twelve departments were partly open. Twenty-two departments relied on unpaid house officer cover at night and weekends (Table 2).

TABLE 2. Staffing establishment for 125 departments

482 full-time equivalents

$63 \%$ senior house officers

$1 / 3$ of senior house officer jobs ( $1 / 5$ total establishment) vacant 1 month or more

3 departments closed at night for lack of staff

16 departments relied on unpaid house officer cover at nights and weekends

The average number of new attendances per doctor was 120 a week or 6280 per annum but the range was extremely wide and varied from thirteen to 315 per week. The average total attendances per doctor was $200 /$ week (Table 3 ). The average number of doctor hours per department was about 260 with a maximum of $550 \mathrm{hr}$ duty. Only twenty-seven departments averaged two or more doctors on duty at the same time. The brunt of the total hours and even more of the night, evening and weekend duty was borne by the senior house officers who averaged $71 \mathrm{hr}$ a week on duty, of which two-thirds was evening, night and weekends. Permanent staff, that is consultants, medical assistants and clinical assistants, averaged $44 \mathrm{hr}$ a week on duty of which one-third was evening, night and weekends (Table 4).

It was shown that consultants working in these departments cost $4 \%$ of the total salaries and contributed only $0.2 \%$ of evening, night and weekend hours. Senior house officers contributed $67 \%$ of evening, night and weekend hours but $58 \%$ of the total cost.

It is clear that the crisis in the staffing of accident and emergency departments is due to the unattractive

TABLE 3.

Average new attendances per doctor

Range wide and varied

Average total attendances per doctor

Maximum doctor hours per department

Average doctor hours per department

Only twenty-seven departments averaged two doctors or more on duty at the same time. 
TABLE 4. Doctor hours worked by grades

\begin{tabular}{|c|c|c|c|c|}
\hline Grade & & $\begin{array}{l}\text { Weekdays } \\
9.00-5.00\end{array}$ & $\begin{array}{c}\text { Evenings } \\
\text { nights } \\
\text { weekends }\end{array}$ & $\begin{array}{c}\text { Total } \\
\text { hr/week }\end{array}$ \\
\hline House officers & average & 40 & 92 & 132 \\
\hline Senior house officers & average & 25 & 54 & 79 \\
\hline Registrars & average & 25 & 41 & 66 \\
\hline Medical assistants & average & 35 & 15 & 50 \\
\hline Clinical assistants & average & 32 & 15 & 47 \\
\hline Consultants & average & 31 & 6 & 37 \\
\hline
\end{tabular}

salary and hours of work of the senior house officer posts which have hitherto been filled by immigrant doctors, the supply of which has been stopped at source and which is likely to decrease still further.

On the evidence obtained the projected effect of creating one new full-time consultant post in each department was shown to increase the cost by $50 \%$ but to increase the available working hours only $4 \frac{1}{2} \%$ and actually to decrease the number of hours available at evening, night and weekends by absorption of existing medical assistants into these posts. This does nothing to solve the problem of 24-hr staffing of departments and cannot be expected to assist the recruitment to existing grades. Surgeons with experience of accident services in which the reception department is under the control of an autonomous consultant are known to express their grave concern at the deleterious effect it has on the total management of the seriously injured.

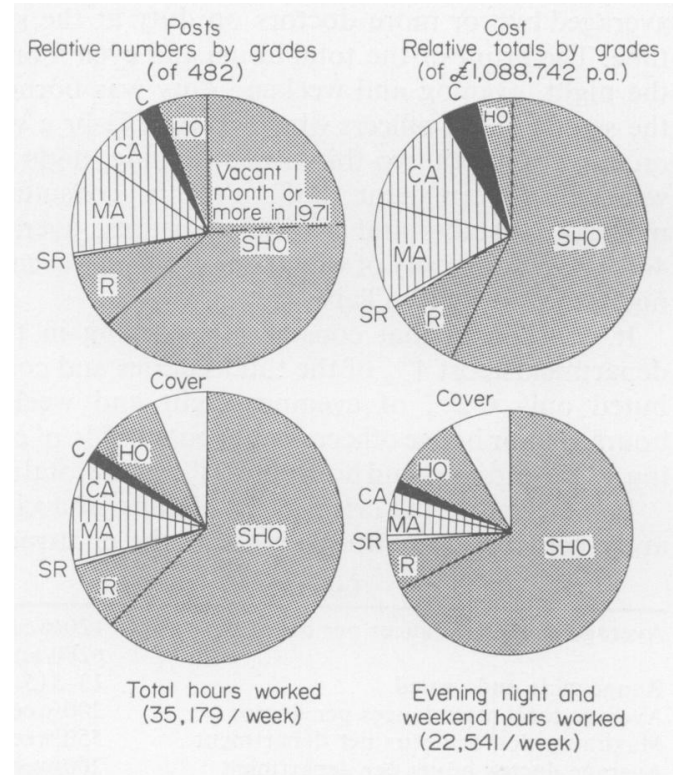

Results of survey - 125 casualty departments
Attempts have been made all over the country to replace senior house officer posts by clinical assistant sessions drawn from general practice. The total contribution of these sessions in these departments was only $5 \%$ of the total hours and $2 \%$ of evening, night and weekend hours at a cost of $14 \%$ of the total. Even if it were possible to replace by clinical assistant sessions, the 128 evening, night and weekend hours in a department previously worked by two senior house officers the cost of doing this would rise from $£ 4080$ to $£ 9000$ per annum. Replies to the survey show that where this policy has been explored amongst local general practitioners, in $50 \%$ of departments no general practitioner was willing to do sessions at any time and in $70 \%$ no general practitioner would do it at the evening or weekends and in $80 \%$ no general practitioner was willing to work at night at the current rate, $£ 28$ per night and $£ 77$ at weekends (Fig. 1).

This information in a preliminary report was presented at a business meeting of the British Orthopaedic Association at Belfast on the 2 April 1971 and the Association unaminously supported a resolution which stated 'We do not support the creation of casualty consultants, we support the view that there should be a consultant in accident and emergency medicine but he should be in charge of the whole accident service including in-patient beds and out-patient clinics, a function already largely taken on by orthopaedic surgeons. There is no place for a consultant in the accident and emergency

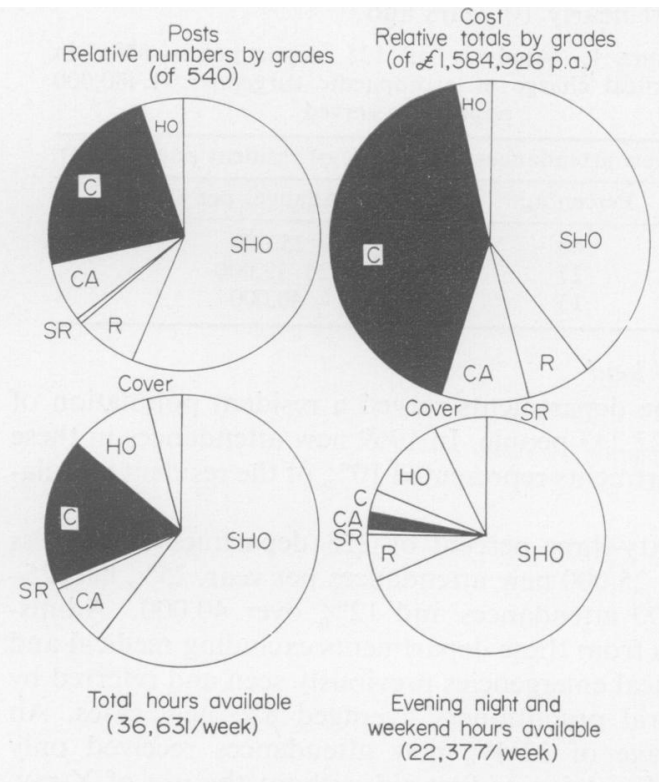

Projected effect of creating one consultant post per department 
department who has no responsibility for the continuing care of the injured patient. Consultants in charge should be enabled to take greater interest in accident and emergency departments and their contracts should have written in sessions working in the department. This would enable them to give time to supervising and organizing the work that goes on in the departments. The staff of the primary care department or reception unit of the accident and emergency department should be under the control of these consultants and must therefore be of subconsultant grade. In larger centres senior house officer posts should be established to train doctors who would be the future reception officers or casualty general practitioners in the department.'

In the British Medical Journal of the 14 August last, Mr Batchelor, President of the British Orthopaedic Association, and I published a letter putting forward the views of the British Orthopaedic Association and among other points mentioned we stated that the appointment of selected casualty officers as consultants in the accident and emergency departments should be undertaken with caution. There are some doctors with higher surgical qualifications who are skilled in casualty work but the British Orthopaedic Association is certain there are insufficient numbers of such men to man the casualty services and does not consider it necessary for them to have consultant status. It emphasises again that the need is for good general doctors in the casualty departments and not highly trained surgeons. When such men are available, the British Orthopaedic Association agrees that they should be employed but that the path of training should be for good general doctors rather than casualty surgeons.

In September at a special meeting held at the Department of Health and Social Security with the Joint Consultants' Committee we again put forward the views of the British Orthopaedic Association that we were in favour of the continued use of orthopaedic surgeons as consultants in charge of emergency departments but accepted that additional sessions were needed and desired at many hospitals to provide adequate cover. We emphasized the importance of ongoing care, especially in the case of minor fractures and injuries which required skilled follow-up treatment to avoid more severe permanent damage. However, the view of the Department and of the Joint Consultants' Committee was that active participation in the work of the emergency department was essential and that organization and supervision were not enough and that it would be necessary to open the field to a wider range of candidates. It was agreed that 'accident and emergency department' was a confusing title and that 'emergency department' would be more suitable. This makes it clear that the discussion has now changed from how to provide for the care of the seriously injured to how to provide general practitioner services on a $24-\mathrm{hr}$ basis in the hospitals. At this meeting we were told that there were 145 senior doctors in casualty departments and that of these 137 were medical assistants, forty-eight of whom possessed the FRCS.

What is to be done? First it is right to mention that an 8-hr day is only one-third of the day and that a 44-hr week is almost one-quarter of the week.

If an experienced doctor is to be in the department for reception $24 \mathrm{hr}$ a day there will have to be at least three doctors a day or four doctors to cover the week and allow for overlap, holidays, etc. It is not possible to cover the department adequately with a casualty consultant working office hours and a skeleton career structure.

If experienced whole-time doctors have to be recruited then over 1000 will be needed. From where are they to come? At present there can be only one source-general practice, and the conditions, hours of work and remuneration will have to compete with general practice; this obviously will not be acceptable to the BMA. A less ideal solution is to recruit medically qualified but not experienced men by making a 6 months period in casualty a requirement for registration of all doctors. This may not be acceptable to the junior hospital doctors group. Perhaps a more practical temporary solution would be to make use of ancillary workers to sort patients, with appropriate safeguards. Reducing the load of work will not affect the staffing problem. The load is clearly within the capacity of the men on duty. It must be accepted that casual attenders will continue to attend and providing that they do not interfere with the work of the department there is no point in them being referred back to their own general practitioner. Such a course would involve the staffing of health centres at night as well as emergency departments and this is uneconomical in view of the shortage of doctors.

Concentration of accident centres will help with the treatment of the seriously injured only if the general practitioner work is not similarly concentrated on a few hospitals with statutory obligation to undertake it. In fact the closing of departments with attendance of under 10,000 new cases per annum has aggravated the problem of the treatment of the injured in accident centres by causing more trivial work to flow to them.

I would like to present to you one last distressing fact. For the first time-at least as far as I can recall-we now have the situation where major London teaching hospitals are so short of staff to man their casualty departments, that large block advertisments for staff are appearing in the journals. The situation is indeed desperate! 